\title{
Adolescentes exibicionistas: a busca de um olhar*1
}

\author{
Jane Glaiby Silva Bastos*2 \\ Isabel Kahn Marin*3
}

\begin{abstract}
Este artigo reflete sobre adolescentes autoras de ato infracional, adotando como ponto de partida a fala habitual da instituição que as acolhia - Fundação de Atendimento Socioeducativo do Pará -, segundo a qual o trabalho com adolescentes do sexo feminino é mais difícil. Buscando respostas para essa formulação emblemática, a partir de entrevistas psicológicas com cinco adolescentes em conflito com a lei, verificou-se que essa dificuldade se associava à exposição que as adolescentes faziam dos genitais no cotidiano institucional, colocando em questão alguns aspectos da sexualidade feminina.
\end{abstract}

Palavras-chave: Adolescentes, conflito com a lei, exibicionismo, sexualidade feminina

${ }^{* 1}$ Artigo baseado na dissertação de mestrado intitulada Transgressão e adolescência feminina: estudo psicanalítico em torno de cinco adolescentes institucionalizadas (2001), orientada pelo Prof. Dr. Manoel Tosta Berlinck. Mestrado Interinstitucional em Psicologia Clínica, convênio Pontifícia Universidade Católica de São Paulo - PUC-SP, Universidade Federal do Pará (UFPA) e Coordenação de Aperfeiçoamento de Pessoal de Nível Superior (Capes).

*22 Universidade do Estado do Pará - UEPA (Belém, PA, Br).

${ }^{*} 3$ Pontifícia Universidade Católica de São Paulo - PUC-SP (São Paulo, SP, Br). 


\section{Adolescentes transgressoras institucionalizadas}

Muito tem sido dito, nas duas últimas décadas, sobre a condição do adolescente em conflito com a lei; entretanto, os estudos sobre $a$ adolescente em conflito com a lei ainda são escassos, refletindo sua invisibilidade social na esteira da mesma invisibilidade que recobre o tema da criminalidade feminina.

No campo da psicanálise, essa realidade não é diferente e, apesar de se encontrar uma significativa literatura, desde Freud, sobre a psicodinâmica da delinquência juvenil, observamos que o tema foi abordado sem a devida distinção de sexo, evidenciando a carência de estudos dessa saída sintomática na adolescente mulher. Desse modo, temos a prevalência de um discurso social, científico e até mesmo psicanalítico que focaliza o adolescente, cujo efeito é certo silêncio sobre o mal-estar que a adolescente em conflito com a lei põe em evidência.

Foi a partir do contato com pedagogos, psicólogos, assistentes sociais e monitores da Fundação de Atendimento Socioeducativo do Pará (Fasepa $)^{1}$ que nos sentimos instigadas por uma questão que pretendemos desenvolver neste artigo. Diziam sentir maiores dificuldades de intervenção psicossocial junto à adolescente que cometeu ato infracional do que em relação ao adolescente, levando-os a recorrentemente declarar: trabalhar com meninas é mais dificil.

Face à similaridade da condição de precariedade socioeconômica e educacional tanto das adolescentes quanto dos adolescentes, bem como dos atos infracionais praticados por ambos os sexos, envolvendo desde a fuga de casa e furtos, uso e tráfico de drogas, até a prática de homicídio, os profissionais da instituição identificavam dois aspectos na questão da adolescente autora de ato infracional, diferentes em relação aos observados em adolescentes do sexo masculino.

$\mathrm{O}$ primeiro referia-se à ausência materna no processo de cumprimento de medida socioeducativa das filhas, diferentemente do que ocorria nas unidades de atendimento aos meninos, nas quais as mães estavam presentes durante o período em que seus filhos deviam responder pela infração cometida, tanto com telefonemas frequentes quanto com visitas semanais.

O segundo elemento identificado como específico da problemática das adolescentes foi a forma como estas presentificavam o corpo na instituição, fazendo

${ }^{1}$ Instituição que coordena a política de aplicação de medidas socioeducativas no Estado do Pará, com dez (10) unidades de atendimento ao adolescente em conflito com a lei. Na ocasião da pesquisa chamava-se Fundação de Amparo à Criança e ao Adolescente (Funcap). 


\section{ARTIGOS}

"coisas" que deixavam os funcionários "sem saber o que fazer": tiravam as roupas na ocasião dos atendimentos por técnicas e monitores e também despiam-se em frente às janelas da instituição à vista de todos, deixavam exposto o sangue menstrual e sujavam as paredes dos banheiros com ele; algumas, recorrentemente desenhavam os genitais durante as atividades pedagógicas, sendo este último aspecto o que chamava a atenção dos profissionais do Centro Socioeducativo Feminino (CSEF) no sentido de alegarem mais dificuldade no trabalho socioeducativo. Portanto, o ato transgressor de exibição do corpo nu nos atendimentos e no dia-a-dia da instituição era o que provocava $o$ mal-estar e o "não saber o que fazer".

Esse artigo pretende aprofundar as questões suscitadas na referida dissertação, principalmente no que diz respeito ao mal-estar frente ao exibicionismo das adolescentes. Recuperou-se o material obtido no processo de entrevistas psicológicas com cinco adolescentes em cumprimento de medidas socioeducativas no CSEF, as quais foram orientadas pela escuta transferencial, conforme o método da psicanálise. É importante observar que, durante a realização das entrevistas, também ocorreram atos de exibição obscena, adotado como elemento de análise, no sentido de buscarmos a singularidade do que ali se expressava, do que se dava a ver nessa exposição do corpo nu e sua função no contexto institucional.

\section{Sobre o exibicionismo}

O termo "exibicionista" deriva do verbo latino exibere, que significa "expor". De acordo com o Manual Diagnóstico e Estatístico de Transtornos Mentais (DSM-IV), o exibicionismo é uma parafilia, um transtorno que envolve a exposição dos próprios genitais a um estranho, geralmente sem qualquer tentativa de atividade sexual adicional com este. Em alguns casos, o indivíduo está consciente de um desejo de surpreender ou chocar o observador; em outros, tem a fantasia sexualmente excitante de que o observador ficará sexualmente excitado.

Segundo Kahr (2010), a exposição dos órgãos genitais a alguém desprevenido, em contextos sociais inapropriados, é um meio de se obter uma gratificação sexual, sendo a maior parte dos exibicionistas homens jovens, embora haja um pequeno número de mulheres que tendem a expor suas partes.

Em sua obra inaugural $A$ interpretação dos sonhos (1900), Freud concedeu importante lugar à ocorrência de sonhos exibicionistas, situando-os entre os sonhos típicos. Estes, em completo contraste com a regra geral de que cada pessoa tem liberdade de construir seu mundo onírico de acordo com suas peculiaridades e assim torná-lo ininteligível para outros, têm, como característica, o fato de que quase todo mundo os possui da mesma forma, com o mesmo sentido, e provenientes da mesma 
fonte. Os sonhos exibicionistas teriam um efeito de embriaguez que o ato de se despir pode causar.

Pois o contexto em que esse tipo de sonhos aparece durante minhas análises de neuróticos não deixa dúvida de que eles se baseiam em lembranças da mais tenra infância. Somente na nossa infância é que somos vistos em trajes inadequados, tanto por membros de nossa família como por estranhos — babás, criadas e visitas; e é só então que não sentimos vergonha de nossa nudez. Podemos observar como o despir-se tem um efeito quase excitante sobre muitas crianças, mesmo em seus anos posteriores, em vez de fazê-las sentir-se envergonhadas. Elas riem e pulam nuas e se dão palmadas, enquanto a mãe ou quem quer que esteja presente as reprova e diz: "Uh, que escândalo!Vocês nunca devem fazer isso!". As crianças manifestam muitas vezes um desejo de se exibirem. É difícil passarmos por um vilarejo do interior em nossa parte do mundo sem encontrarmos uma criança de dois ou três anos levantando a camisinha diante de nós - em nossa homenagem, talvez. (Freud, 1900/1992, p. 272)

Ao declarar que qualquer homem ou mulher adulto incorreu, no passado, em formas de exposição genital, disso extraindo prazer, Freud nos ajuda a compreender não apenas o importante papel da exibição genital no desenvolvimento da criança comum, na esteira do que podemos chamar de condição exibicionista da humanidade, mas também que a persistência desse impulso infantil de exibir-se, que permanece fixado no estágio perverso polimorfo, alcança o nível de um sintoma, configurando a categoria dos exibicionistas.

A maior contribuição de Freud para o estudo do comportamento exibicionista foi sem dúvida a sua insistência no fato de cada um de nós começar a sua vida sob a forma de uma criança exibicionista, caracterizando-se o perverso falhar na tarefa que, no entanto, a maior parte de nós acaba por ser capaz de levar a cabo - de conter os impulsos de exibição indevida. (Kahr, 2010, p. 59)

Mas foi em "Três ensaios sobre a teoria da sexualidade" (1905/1992) que Freud deu a mais significativa contribuição para o estudo dos atos de desnudamento exibicionista, considerados como desvio do alvo sexual.

Por outro lado, o prazer de ver [escopofilia] transforma-se em perversão (a) quando se restringe exclusivamente à genitália, (b) quando se liga à superação do asco (o voyeur) - espectador das funções excretórias, ou (c) quando suplanta o alvo sexual normal, em vez de ser preparatório para ele. Este último é marcadamente o caso dos exibicionistas que, se posso deduzi-lo após diversas análises, exibem seus genitais para conseguir ver, em contrapartida, a genitália do outro. (p. 148-149)

De acordo com Freud, portanto, podemos dizer que o sujeito exibicionista faz desse expediente um apelo ao espectador para que este também se exiba, ao modo de 


\section{ARTIGOS}

uma relação especular. Temos assim, nos textos freudianos, o exibicionismo entendido como um sintoma da perversão, cujo desejo seria de obtenção de uma imagem especular. Se o exibicionismo é um sintoma da perversão, como pensar os atos exibicionistas das adolescentes em conflito com a lei? Seriam tais adolescentes perversas? E mais, seria esse viés nosográfico útil para nossa análise?

A tendência a diagnosticar essas adolescentes na lógica da perversão não deixa de ser controversa. De um lado, temos Bloss (1998), num dos raros estudos sobre a adolescente delinquente, que a situa na lógica da perversão por se expressar, na maioria das vezes, pela atuação sexual. De outro lado, temos a posição de Rassial (2004), que indica a histeria como possibilidade diagnóstica, diferenciando três tipos de delinquência feminina: o primeiro, que chama de pseudodelinquência histérica, refere-se a procurar o pai em algum lugar, o que se observa na garota que passa seu tempo roubando vestidos ou roupas, mais próxima da cleptomania do que da delinquência. $\mathrm{O}$ segundo tipo, provavelmente histérico também, envolve oferecer o corpo como objeto: já que a garota não é objeto de desejo do pai, será objeto de desejo de um homem, o que pode ser observado na prostituição. E o terceiro tipo é o de uma identificação masculina, observado em meninas que integram bandos.

Em que pese o valor diagnóstico como um recurso que orienta a escuta e baliza o processo de intervenção clínica, salientamos que a consideração pela singularidade das histórias, bem como o risco de incorrermos em generalizações, não nos permite adotar aqui essa vertente nosográfica, pois, apesar de as cinco adolescentes entrevistadas apresentarem similaridades em seus atos, como já dissemos, elas formularam respostas subjetivas diferenciadas para os impasses de seus percursos de vida. Ademais, "o que define o diagnóstico em psicanálise não é a conduta. O que define o diagnóstico em psicanálise é a posição subjetiva frente ao sintoma" (Leite, 1999, p. 39).

Se o exibicionismo evoca o olhar, foram o deslocamento deste para a escuta do que estava em jogo nesse sintoma das adolescentes e principalmente o sofrimento psíquico ali implicado que nos inquietaram. Essa postura ética nos conduziu a tomar a condição adolescente, e particularmente as vicissitudes da adolescência feminina, como eixo condutor da análise, a fim de encontrar referências conceituais que balizassem uma compreensão da expressão sexualizante e exibicionista dessas adolescentes.

\section{Adolescência feminina e o arcaico feminino}

A adolescência, apesar de não ser uma categoria originária da psicanálise, vem no interior desta ganhando progressivamente corpulência teórica, delineando, enfim, os elementos para uma teoria do "pubescer" e do "adolescer". As modalidades de 
abordagem desse período têm se mostrado bastante discutíveis, destacando-se formas de entender a adolescência seja como crise, processo ou transformação (Raymond, 1999).

Entendemos a adolescência não como uma fase evolutiva produzida por um suposto desenvolvimento natural, mas, na perspectiva de Ruffino (1995), como uma instituição histórica e como uma operação psíquica. Enquanto instituição histórica, a adolescência seria uma resposta à redução ou até mesmo ao desaparecimento da ritualização dos momentos cruciais no ciclo da vida, na medida em que o púbere moderno, ante as exigências das mudanças corporais e a convocatória do outro para que se situe entre os adultos, não encontra procedimentos sociais eficazes para significar esse momento de passagem. "Na impossibilidade de normativizar-se consigo, o púbere moderno adolesce" (p. 42). Marin (2009) também destaca os efeitos do desaparecimento, na contemporaneidade, dos ritos tradicionais de passagem que acolhiam os jovens:

Hoje o jovem é levado a produzir singularmente dispositivos que lhe permitam a construção de um sentido para a estranheza com a qual se defronta num momento de passagem. Temos assim a ilusão de que cada um deve mostrar do que é capaz a partir de critérios absolutamente individuais, o que lança o sujeito a um desamparo paradoxalmente constituído pela ilusão de ter direito à expressão e à vontade singular. (p. xxxiv)

Enquanto operação psíquica, a adolescência seria um verdadeiro trabalho psíquico visando abordar, entre outras questões,

(...) o despertar (...) da experiência que arranca o sujeito da infância - que a puberdade introduz no sujeito ao findar da latência sexual, despertar que visa operar o seu acesso ao Outro-sexo, esse despertar se introduz não imediatamente como um passaporte para essa travessia, mas antes como um Real que sidera o sujeito. Para que fosse dessideralizado, o sujeito necessitaria da intervenção sobre ele de uma operação, a se esperar da instância simbólica da Paternidade, que, assim como esta interveio na estrutura edipiana constituindo-lhe inauguralmente a subjetividade através da interdição do incesto, viesse a ressurgir agora, não mais para proibir a endogamia, mas para possibilitar, se não para exigir - a exogamia. (Ruffino, 1997, p. 39)

Assim, enquanto operação psíquica, a adolescência não seria uma etapa cronológica, mas um trabalho do sujeito para ultrapassar a sideração que as convocações da puberdade, do Outro-sexo e da cultura provocam, num tempo histórico marcado pela ausência de ritualização desse momento crucial do ciclo da vida.

Do ponto de vista dos processos psíquicos, sabemos que na adolescência estágios primitivos da constituição do sujeito são reanimados, ocupando muitas vezes o centro da conflitualidade na adolescência. Em que pese o significativo avanço nos estudos psicanalíticos sobre a adolescência, e também sobre a subjetividade feminina, podemos observar que em ambos os campos temáticos há muito para se investigar sobre a adolescente. 


\section{ARTIGOS}

Vale dizer que foi o discurso de mulheres jovens que guiaram Freud em suas primeiras pesquisas, o qual deixou importantes indicações sobre a dinâmica inconsciente dos anos de juventude da mulher em "A sexualidade feminina" (1931/1992). Nesse trabalho, Freud nos ensina que grande parte dos anos da juventude da mulher são ocupados numa luta com suas mães, fruto da tarefa que a mesma tem de fazer para trocar de objeto amoroso, o que faz com que muitos fenômenos desse período só possam ser compreendidos por referência à fase pré-edipiana da menina, em que a mãe é o primeiro objeto amoroso.

Essa fase entre a menina e sua mãe, a princípio negligenciada por Freud, ao ser retomada ante a descoberta da intensa e longa duração da relação que as une, produziu um efeito de surpresa no mestre vienense:

Nossa compreensão interna dessa fase primitiva, pré-edipiana, nas meninas, nos chega como uma surpresa, tal como a descoberta, em outro campo, da civilização mino-miceniana por detrás da civilização da Grécia. (Freud, 1931/1992, p. 234)

A questão é que, ante a descoberta desse universo arcaico feminino, de relação fusional e da ligação irredutível da relação mãe-filha, "Freud trouxe à luz uma questão espinhosa num outro sentido, que é a do desligamento" (Assoun, 1993, p. 103), posto que a menina terá de se desligar desse porto seguro para aceder ao pai. Para isso Freud (1931/1992) enumerou "os mecanismos em ação em seu afastamento da mãe" (p. 239), advertindo-nos sobre a pluralidade de fatores que passam a operar juntos para esse fim.

O novo estatuto da condição adolescente reanima essa relação entre a menina e sua mãe, na maioria das vezes a despeito da própria interessada, colocando em jogo novamente os desafios do sujeito filha para se afastar de sua mãe. É, portanto, no registro da natureza da relação da menina com sua mãe que pensamos elucidar os atos exibicionistas das adolescentes entrevistadas.

Uma das especificidades dessa relação está no fato da menina ter de mudar de objeto amoroso para desenvolver seu senso de integração e sua feminilidade, diferentemente do menino que não precisa se defrontar com a mudança do sexo do objeto amoroso, no caminho para a masculinidade.

Nessa ligação com a mãe, além de definir-se a relação com o objeto, vão se configurando, na sua ambivalência, as razões das diferenças psíquicas entre meninos e meninas, cuja principal distinção derivaria não das diferenças anatômicas de seus sexos, mas das relações vividas com a mãe, que refletem como ela própria experiencia a sua sexualidade, suas percepções sobre as diferenças sexuais e como as exprime para seus filhos.

Nesse registro, a ambivalência afetiva materna se mostraria mais presente e mais ativa nas relações entre mãe e filha do que entre mãe e filho. Essa face hostil mais presente em relação à filha é destacada por Freud quando este aborda 
o temor que algumas mulheres têm de serem mortas (devoradas) pela mãe. Esse temor corresponderia a uma hostilidade desenvolvida na criança em consequência das restrições impostas no decorrer do treinamento e do cuidado corporal: "É impossível dizer quão frequentemente esse temor da mãe é apoiado por uma hostilidade inconsciente por parte desta, hostilidade que é pela menina" (Freud, 1931/1992, p. 245).

É nesse sentido que Le Guen (1997) ressalta que a fase pré-edipiana da menina se desenrola no registro da agressividade. Desse modo, desde os tempos mais precoces, o que funda então a diferença entre os sexos é a ambivalência materna que, presa na identificação narcísica, só pode aparecer mais marcada em direção à filha do que ao filho; assim, organiza-se a divergência de seus destinos: a menina, diferentemente do menino, vê-se remetida mais ao sujeito do que ao objeto, ao ser mais do que ter.

Tudo se passa como se o menino estivesse "protegido" pela evidência da sua diferença, carreada por seu corpo e projetada sobre seu pênis; ele proporciona assim à mãe uma satisfação narcísica (ele é o seu "falo glorioso"), que ela lhe devolve e que lhe permite então se pensar como filho preferido. A esta satisfação, sua filha contrapõe uma identificação narcísica, mistura de plenitude gratificante e de incerteza frustrante (para ambas, aliás), num jogo de espelhos; daí esta ambivalência mais marcada com a mãe em relação à filha, que determina, ocasionalmente, uma paixão mais forte, de onde a "violência" mais próxima na ambivalência, quer para amar ou para odiar. (...) eu diria que o menino é mais facilmente um "objeto" para sua mãe, enquanto a menina vem também interrogá-la enquanto “sujeito”. (p. 13)

Residiria aí uma das razões da ausência materna nas visitas às adolescentes no CSEF, isto é, na possibilidade de as adolescentes agora questionarem suas mães por seus destinos? Ou estariam em jogo elementos para além dessa relação particular da menina com sua mãe que, como já vimos, é em si marcada por certa dose de agressividade?

Luciene, 15 anos, praticante de furto, delito que a levou pela terceira vez ao então CIAF, relata não se dar bem com sua mãe e se envergonhar dela. Chegou a pensar não ser sua filha, pois sua mãe a escondia de outras pessoas e, segundo Luciene, sua mãe dizia "que não sou filha dela".

Cristina, 15 anos, apesar de ter sido levada ao CIAF por envolvimento com tráfico de drogas, fala que participou de dois homicídios, primeiro da morte de um taxista e depois de uma moça que testemunhara o primeiro homicídio. Relatou que sua mãe a entregou a uma família de outro Estado quando tinha dois meses de idade, e aos 13 anos foi devolvida por mau comportamento. A realização do antigo desejo de reencontrar a mãe biológica foi acompanhada de intensa decepção: "Quando eu chegava assim drogada à noite, ela me colocava fora de casa, eu nem tinha onde dormir. Ela não me dava conselho". 


\section{ARTIGOS}

Observamos que é nesse complexo registro da relação mãe-filha que essas adolescentes localizam muitas de suas questões, sinalizando os efeitos nefastos das relações com suas mães. Sentem não ter ocupado lugar privilegiado no desejo materno, marcando-as como sujeitos mal investidos pela libido materna. Expressam as humilhações pelas quais passaram, as vivências de abandono, separação ou perda do amor materno ocorridas na sua realidade histórica. Entendemos aqui por realidade histórica "o relato, feito pelo próprio sujeito ou por um terceiro, através do qual tomamos conhecimento dos acontecimentos que, efetivamente, marcaram a infância do sujeito" (Aulagnier, 1979, p. 216). Ora, o fato de as mães dessas adolescentes não atenderem suas necessidades amorosas é um dado da maior importância na compreensão do mecanismo psíquico de engajamento infrator e exibicionista, possivelmente ordenado por uma demanda insatisfeita, dirigida ao outro materno, com o qual só mantém uma relação conflituosa.

\section{Operação adolescer, exibicionismo e complexo de castração}

De acordo com Winnicott (2005), o desenvolvimento da capacidade sexual na adolescência inclui formas próprias de organização de defesas contra ansiedades de vários tipos, ou seja, "restam todos os tipos de padrões doentios associados a falhas de amadurecimento em nível edípico ou pré-edípico" (p. 117). Nesse sentido, a fim de colocar em marcha a separação dos pais e tomar posse de si, ante o perigo de retorno à mãe pré-edípica, a adolescente busca uma solução:

De qualquer modo, observamos na adolescência feminina uma pressão regressiva que exerce sua influência na direção de um retorno à mãe pré-edípica. Essa pressão regressiva, determinada em seu vigor pela fixação existente, encontra reação no exercício da independência excessiva, na hiperatividade e uma inclinação vigorosa para o outro sexo. (Bloss, 1998, p. 309)

Em se tratando das adolescentes exibicionistas, no que a operação adolescer traz riscos de recolocar essas vivências arcaicas e as condições psíquicas para essa operação parecem ser insuficientes, a travessia adolescente torna-se turva e mais difícil, colocando em jogo, por meio do sintoma exibicionista, o complexo de castração.

Em termos simbólicos, o complexo de castração compõe, com o complexo de Édipo, aquilo que funda e institui o sujeito em sua relação com o mundo. Enquanto experiência psíquica, o complexo de castração é uma fantasia que meninos e meninas formulam frente ao enigma da diferença anatômica entre os sexos, referida à ausência de pênis na menina. O menino teme a castração como realização de uma ameaça paterna em resposta às suas atividades sexuais, surgindo daí uma intensa angústia de castração. Na menina, a ausência do pênis é sentida como um dano sofrido que ela procura negar, compensar ou reparar. 
O complexo de castração aponta, assim, para a radicalidade da diferença sexual, exigindo do sujeito uma tomada de posição. Na adolescência, esse posicionamento deve ser operado novamente, devendo o sujeito retificar ou ratificar sua posição na partilha dos sexos, o que significa reviver a castração e as marcas deixadas pela infância. A reedição da castração é uma oportunidade, ainda que psiquicamente difícil, de o adolescente tomar em mãos sua história, responsabilizar-se por sua herança e se inscrever no mundo adulto como ser sexuado e com limites. Entretanto, para as adolescentes em conflito com a lei, tal possibilidade parece bastante ameaçadora, haja vista significar, a despeito da heterogeneidade das histórias, a retomada de um percurso com o qual não querem se confrontar.

Nesse sentido, as atitudes exibicionistas de colocarem os seios à mostra, de sujarem de sangue menstrual as paredes dos banheiros da instituição, de fazerem insinuações sobre as dimensões do clitóris, como argumento de poder e de exposição do órgão genital, estariam regidas por processos psíquicos referidos ao complexo de castração? Estaria aí operando algo da ordem do que Freud (1927/1992) isolou como uma defesa frente à diferença anatômica entre os sexos, o mecanismo da denegação (desmentido) frente à castração? O tema é muito vasto, o que não nos permite desenvolvê-lo aqui. Destarte, sobressaíram-se, como fio condutor de nossa análise, os efeitos das transformações da puberdade referentes à particularidade da relação mãe-filha vividas pelas adolescentes exibicionistas.

Interpeladas pelas transformações — biológicas e erógenas — que esse segundo tempo do desenvolvimento da sexualidade humana introduz, cujas manifestações configuram-se, no sexo feminino, no aparecimento da menstruação cíclica, no crescimento dos seios e no potencial reprodutivo, algumas das adolescentes, por lhes parecerem tais mudanças enigmáticas, adotam um modo bastante peculiar de lidar com as mesmas, isto é, colocando em cena elementos próprios da sexualidade feminina: seios, menstruação e vulva.

É que, não encontrando respostas para as mudanças corporais pelas quais passam, adotam tais mudanças como instrumento de exibição, posto que tais mudanças parecem ser vividas como algo violento, dado o caráter desarticulante de não ter ninguém a quem dirigir-se, ninguém com quem falar. Vivem um estado de inquietude, confusão e desagregação. Assim, na impossibilidade de pensamento e de elaboração psíquica, ao se exporem visam que o outro, em reação, ofereça um sentido. Sentido arrancado, possível, por meio da exibição dessas mudanças e de seus fluidos.

O corpo, como um todo, desempenha uma função bem específica na economia psíquica das adolescentes ouvidas. Ele precisa, além de ser visto, ser exposto imaginariamente nos seus orifícios, dimensões, posições, e em suas entranhas, como se pode observar na fala: “É só a tia chegar, me dá vontade de peidar, de dar um tiro". Imagem bizarra, em que a presença do outro desperta o desejo de seu aniquilamento e em que o corpo faz às vezes de instrumento bélico. 


\section{ARTIGOS}

O genital feminino é evocado várias vezes no dia a dia institucional, seja na sua exibição para as educadoras, seja na exacerbação de um discurso que insinue suas dimensões e sensações, como se observa no fragmento: "O guarda quase me bateu, olha, nem a minha mãe que abriu o xiri dela para me ter faz isso comigo!' É assim que Juliana desautoriza a agressão empregada por um policial na detenção que a levou ao CSEF, valendo-se de um verdadeiro "cenodrama vaginal" (tomando de empréstimo uma expressão de Baudrillard, 1992). É assim, como dilaceramento e esgarçamento corporal, que representa seu nascimento e talvez a reprodução.

Considerando o lugar que o corpo ocupa na estruturação psíquica do sujeito, e especialmente as diferenças anatômicas entre os sexos, é adequado pensar que a natureza das angústias e os conflitos do sexo feminino seriam necessariamente diferentes das do sexo masculino.

Segundo Bernstein (1998), a tarefa de integração da própria genitália à imagem corporal seria uma das tarefas da organização psíquica do sujeito, sendo que, em contraste com a masculina, a genitália feminina, pelas suas características, geraria três tipos de angústias genitais femininas: de acesso, de difusão e de penetração. Tais angústias estariam relacionadas, respectivamente, à dificuldade visual e tátil de acesso ao próprio genital; à difusão das sensações para outras áreas, como a do clitóris para a vagina, região pélvica, uretral e anal; e ao desconhecimento sobre a lubrificação e elasticidade do órgão.

Nesse sentido, tal exposição pode ser compreendida como uma resposta ao enigma que as mudanças pubertárias trazem para essas adolescentes, que usam seus corpos para que o outro, em reação, ofereça um sentido, ainda que arrancado a partir do efeito de surpresa promovido. Quando Luciene olhava para um pôster de anatomia na pequena biblioteca do CSEF e formulou a questão " $E$ assim que somos por dentro?", esta expressava sua perplexidade ante a complexa relação entre corpo e conhecimento.

Não saber expressar e não saber compreender compõem a experiência de conhecimento. Além disso, conhecer e ignorar estão apoiados na vivência interna psíquica - de ódio e de castração. Apontam o duro caminho a ser percorrido pelo espírito humano em suas tentativas de construir a mãe como objeto de amor, passível de decifração. (Tomazelli, 1998, p. 23)

Se o processo adolescer implica angústias em relação ao corpo em mudança, à apropriação do corpo sexuado (Cahn, 1999, p. 55), recolocando em cena para a menina adolescente a antiga e complexa relação com sua mãe, o que dizer desse processo no caso de adolescentes em conflito com a lei e sob cumprimento de medidas socioeducativas?

Pensamos que é no âmago da relação mãe-filha que o exibicionismo das adolescentes em conflito com a lei ganha sentido, pois adolescer, para elas, significa 
entrar em contato com lembranças extremamente difíceis. Para Luciene, a de uma mãe com "problemas na cabeça", que a escondia das visitas; para Juliana, vivências de maus-tratos, alcoolismo e drogadição materna; para Claúdia, incentivo à prostituição, e para Cristina e Mariza, abandono materno.

A adoção da relação mãe-filha como referência para analisar o exibicionismo dessas adolescentes apoiou-se também na observação de que a exibição dirigia-se principalmente às profissionais femininas da instituição, o que evidenciava uma demanda endereçada às mulheres, possivelmente, articulada ao drama da formulação da identidade sexual. Consideramos, assim, que uma das fontes das manifestações exibicionistas dessas meninas reside na relação com a mãe pré-edípica. Portanto, tal exposição estaria ligada aos efeitos mais arcaicos da homossexualidade feminina, da sedução junto à mãe, fixada num padrão defensivo frente à carência ou à impossibilidade de a mãe de responder às suas demandas.

Nesse sentido, o exibicionismo pode ser entendido sob duas perspectivas, mas de qualquer forma referido ao "rochedo da castração". Primeiro, como forma de defesa, ao modo de uma máscara de horror pois, segundo Freud, a visão dos órgãos genitais femininos provocariam um horror comparável ao que desperta a visão da "A cabeça de Medusa" (1940), sendo tal terror da Medusa um terror de castração. Daí o sentido de desafio que impunham aos profissionais da instituição, numa atuação da disposição perversa polimorfa da sexualidade, em que o exibicionismo teria a função de defesa, de evitação da possibilidade de vínculo com aquelas profissionais, num desdobramento dos efeitos nefastos de terem sido precariamente investidas afetivamente pelo objeto primordial. E neste ponto, vale dizer, conforme Zalcberg (2003), que a angústia de castração não é aplicável à menina, ela não pode temer o que já ocorreu. O que a ameaça é o medo de não ser amada e a falta de um símbolo específico da sexualidade feminina. A falta da angústia de castração pode ser uma dificuldade da menina de elaborar o seu Édipo, podendo sair dele lentamente ou nunca sair realmente.

Na segunda perspectiva, o exibicionismo teria a função de avaliação da capacidade do outro de suportar o que vê, sem se deixar paralisar e petrificar pelo visto. Embora na adolescente, de um modo geral, haja um exibicionismo acentuado, cujo fundamento concerne ao engajamento que esta faz em relação ao olhar do outro — e daí advindo seus enfeites, cores (Rassial, 1999), as adolescentes do CSEF, como aqui pontuado, faziam dessa exibição não um oferecimento para admiração, mas para provocar um desconcertante impacto.

Nesse sentido, entendemos que a frase dos funcionários da Funcap "Trabalhar com meninas é mais difícil" seria a expressão inconsciente de uma angústia de castração, revivida na cena exibicionista pelos profissionais da instituição, que deveriam passar pela prova que tais adolescentes lhes impunham em relação aos enigmas da sexualidade feminina e à demanda por um outro olhar, que as remete às relações arcaicas com suas mães. 


\section{Referências}

Associação Psiquiátrica Americana (APA). (2002). DSM-4-TR TM. Manual Diagnóstico e

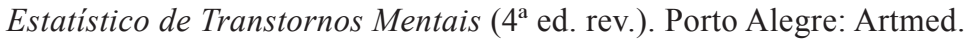

Assoun, P.-L. (1993). Freud e a mulher. Rio de Janeiro: Jorge Zahar.

Aulagnier, P. (1979). A violência da interpretação: do pictograma ao enunciado. Rio de Janeiro: Imago.

Baudrillard. (1992). Da sedução. Campinas, SP: Papirus.

Bernstein, D. (1998). Angústias genitais femininas, conflitos e modos típicos de domínio. In D. Breen (Org.). O enigma dos sexos: perspectivas psicanalíticas contemporâneas da feminilidade e da masculinidade. Rio de Janeiro: Imago.

Bloss, P. (1998). Adolescência: uma interpretação psicanalítica. (2a ed.). (Waltensir Dutra, trad.). São Paulo: Martins Fontes.

Cahn, R. (1999). O adolescente na psicanálise: a aventura da subjetivação. (Sandra Regina Felgueiras, trad.). Rio de Janeiro: Companhia de Freud.

Freud, S. (1992). A interpretação dos sonhos. In Edição Standard Brasileira das Obras Psicológicas Completas de Sigmund Freud (Vol. IV e V). Rio de Janeiro: Imago. (Trabalho original publicado em 1900).

Freud, S. (1992). Três ensaios sobre a teoria da sexualidade. In Edição Standard Brasileira das Obras Psicológicas Completas de Sigmund Freud (Vol. VII). Rio de Janeiro: Imago. (Trabalho original publicado em 1905).

Freud, S. (1992). Sexualidade feminina. In Edição Standard Brasileira das Obras Psicológicas Completas de Sigmund Freud (Vol. XXI). Rio de Janeiro: Imago. (Trabalho original publicado em 1931).

Freud, S. (1992). A cabeça de Medusa. In Edição Standard Brasileira das Obras Psicológicas Completas de Sigmund Freud (Vol. XVIII). Rio de Janeiro: Imago. (Trabalho original publicado em 1940[1922]).

Kahr, B. (2010). Exibicionismo. São Paulo: Almedina.

Le Guen, C. (1997, $1^{\circ}$ sem.). O engodo feminino do masoquismo ordinário. Percurso. Revista de Psicanálise, São Paulo, IX(18), 12-13.

Leite, M. P. de S. (1999, abril). A psicanálise como diagnóstico da psiquiatria. Pulsional Revista de Psicanálise, São Paulo, XII(120), 36-40.

Marin, I. da S. K. (2009). A clínica institucional da adolescência (Entre o aborrecente e o herói: quem é o adolescente na escuta psicanalítica?). Rev. Bras. Adolescência e Conflitualidade, 1(1), xxxii-xlii. Disponível em: <http://periodicos.uniban.br/index.php/ RBAC/issue/view/10> Acesso em: 02 dez. 2012.

Rassial, J.-J. (1999). O adolescente e o psicanalista. Rio de Janeiro: Companhia de Freud.

Rassial, J.-J. (2004, $1^{\circ}$ sem.). Questões pós-modernas e psicanálise. Percurso. Revista de Psicanálise, São Paulo, XVII(31/32), 135-148. 
Ruffino, R. (1995, nov.). Adolescência: notas em torno de um impasse. Adolescência. Revista da Associação Psicanalítica de Porto Alegre, V(11), 41-46.

Ruffino, R. (1997, mar.). Adolescência e puberdade. Pulsional. Boletim de Novidades, São Paulo, $X(95), 37-47$.

Tomazelli, E. (1998). Corpo e conhecimento: uma visão psicanalítica. São Paulo: Casa do Psicólogo.

Zalcberg, M. (2003). A relação mãe e filha. Rio de Janeiro: Elsevier.

Winnicott, D. W. (2005). A família e o desenvolvimento individual. (3 $3^{\text {a }}$ ed.). São Paulo: Martins Fontes.

\section{Resumos}

(Exhibitionistic teenage girls: wanting to be seen)

This article discusses female juvenile offenders, taking as its starting point the habitual discourse of the institution where they were detained - Fundação de Atendimento Socioeducativo do Pará. According to staff members, it is more difficult to treat female patients. Seeking answers to this emblematic formulation, and based on psychological interviews with five juvenile offenders, we found that this difficulty was associated with the fact that such girls often exposed their genital areas during their institutional routines. This brings up certain aspects of female sexuality.

Key words: Adolescents, delinquency, exhibitionism, female sexuality

(Adolescentes exhibitionnistes: à la recherche d'un regard)

Cet article propose une réflexion sur les jeunes-filles adolescentes auteurs d'infractions en prenant comme point de départ le discours habituel de l'institution qui les accueillit - la Fundação de Atendimento Socioeducativo do Pará - selon laquelle le travail avec les jeunes filles adolescentes est plus difficile. Pour découvrir ce qui mène à cette formulation emblématique, nous avons réalisé des entretiens psychologiques avec cinq adolescentes en conflit avec la loi et nous avons constaté que cette difficulté est associée au fait que ces adolescentes exposent leurs organes génitaux dans la routine institutionnelle, ce qui met en question certains aspects de la sexualité féminine.

Mots clés: Filles adolescentes, conflit avec la loi, exhibitionnisme, relation mère-fille, sexualité féminine

(Adolescentes exhibicionistas: la búsqueda por una mirada)

Este artículo presenta una reflexión sobre adolescentes autoras de acto infracional, adoptando como punto de partida el discurso habitual de la institución que las am- 
paraba,la Fundação de Atendimento Socioeducativo de Pará, según la cual el trabajo con adolescentes del sexo femenino sería más difícil. Buscando respuestas para esta formulación emblemática, a partir de las entrevistas psicológicas con cinco adolescentes en conflicto con la ley, se verificó que esta dificultad estaba asociada a la exposición que las adolescentes hacian de sus genitales en la rutina institucional, cuestionando algunos aspectos de la sexualidad femenina.

Palabras clave: Adolescentes, conflicto con la ley, exhibicionismo, sexualidad femenina

(Exhibitionistische Jugendliche: Die Suche nach einem Blick)

Dieser Beitrag ist eine Reflexion über junge Mädchen, die ein Vergehen begangen haben, ausgehend von der üblichen Redensart in der sozial-erzieherischen Einrichtung, die sie aufgenommen hat, Fundação de Atendimento Socioeducativo do Pará. Laut dieser Einrichtung ist die Arbeit mit jungen Mädchen schwieriger als mit Jungen. Auf der Suche nach Erklärungen für diese emblematische Feststellung, ausgehend von psychologischen Interviews mit fünf Jugendlichen, die rechtswidrig gehandelt hatten, kam man zu dem Schluss, dass dieses Problem in Zusammenhang mit der alltäglichen Verhalten dieser Jugendlichen stand, die ihre Genitalien in der Institution zur Schau stellten. Folglich warf dies Fragen bezüglich Aspekten der weiblichen Sexualität auf.

Schlüsselwörter: Jugendliche, Konflikte mit dem Gesetz, Exhibitionismus, weibliche Sexualität

Citação/Citation: Bastos, J. G. S. \& Marin, I. K. (2014, junho). Adolescentes exibicionistas: a busca de um olhar. Revista Latinoamericana de Psicopatologia Fundamental, 17(2), 175-190.

Editor do artigo/Editor: Manoel Tosta Berlinck

Recebido/Received: 5.3.2013/ 3.5.2013 Aceito/Accepted: 7.7.2013 / 7.7.2013

Copyright: (C) 2009 Associação Universitária de Pesquisa em Psicopatologia Fundamental/ University Association for Research in Fundamental Psychopathology. Este é um artigo de livre acesso, que permite uso irrestrito, distribuição e reprodução em qualquer meio, desde que o autor e a fonte sejam citados / This is an open-access article, which permits unrestricted use, distribution, and reproduction in any medium, provided the original authors and sources are credited. 
Financiamento/Funding: As autoras declaram não ter sido financiadas ou apoiadas / The authors have no support or funding to report.

Conflito de interesses/Conflict of interest: As autoras declaram que não há conflito de interesses / The authors declare that has no conflict of interest.

\section{Jane Glaiby Silva Bastos}

Psicóloga; Mestre em Psicologia Clínica pela Pontifícia Universidade Católica de São Paulo - PUC-SP (São Paulo, SP, Br); Professora da Universidade do Estado do Pará - UEPA (Belém, PA, Br). Tem experiência na área de direitos humanos e violência (atendimento de vítimas de trabalho escravo, tortura e familiares de vítimas de homicídio); com sujeitos em vulnerabilidade social (crianças, adolescentes, mulheres e negros), em psicologia institucional.

Travessa Padre Eutiquio, 2527/102-b - Indaiá

66033-000 Belém, PA, Br

Fone: (91) 8842-8342

e-mail: janeglaiby@hotmail.com.br

\section{ISABEL KAHN MARIN}

Psicóloga; Psicanalista; Doutora em Psicologia Clínica pela Pontifícia Universidade Católica de São Paulo - PUC-SP (São Paulo, SP, Br); Membro da Associação Universitária de Pesquisa em Psicopatologia Fundamental (São Paulo, SP, Br); Vice-presidente da ABEBE - Associação de Estudos sobre o Bebê (Brasília, DF, Br); Professora, pesquisadora e supervisora clínica/institucional do Curso de Psicologia da FACHS da PUC-SP nas áreas da infância, juventude e família; Responsável pelo Aprimoramento Clínico Institucional de Casal e Família, oferecido pela Clínica Psicológica "Ana Maria Popovic" da PUC-SP; Supervisora clínica e institucional de profissionais envolvidos em programas de atenção à saúde, educação, assistência e justiça.

Rua Capote Valente, 439/113

05409-001São Paulo, SP, Br

Fone: (11) 3081-1829

e-mail: belkahn@gmail.com 